\title{
innovaciones en la construcción de silos SUIZA
}

A. HUONDER, Dipl. Ing.

P. VAJDA, Dipl. Ing. colaborador

$582-11$

sinopsis Se describen en el articulo las caracteristicas, dimensiones, sistemas constructivos, sellado de juntas, encofrados, montaje, etc., de estos silos totalmente prefabricados, que constituyen una novedad destacada en cuanto a rapidez de ejecución, perfección de acabado y gran economía.

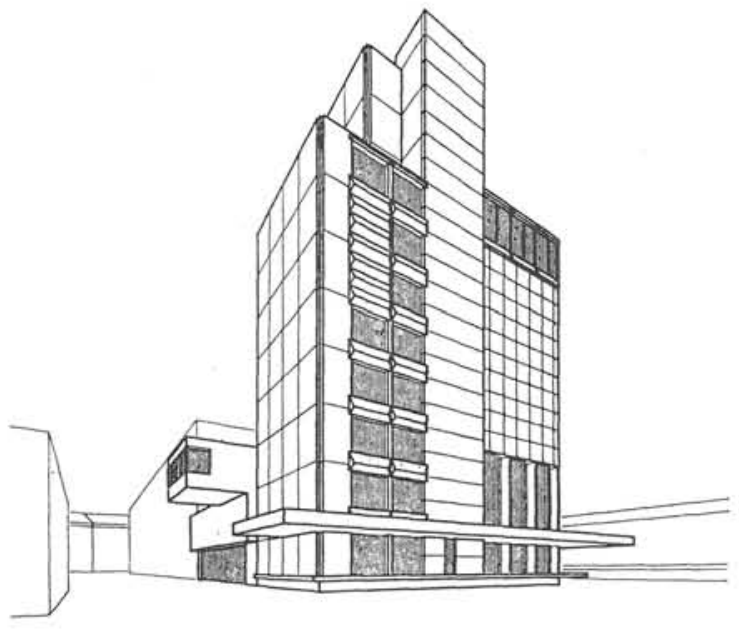

Fig. 1. Fábrica de piensos compuestos vLGz. Mixed-fodder factory VLGZ. Usine pour fourrages mélangés VLGZ.

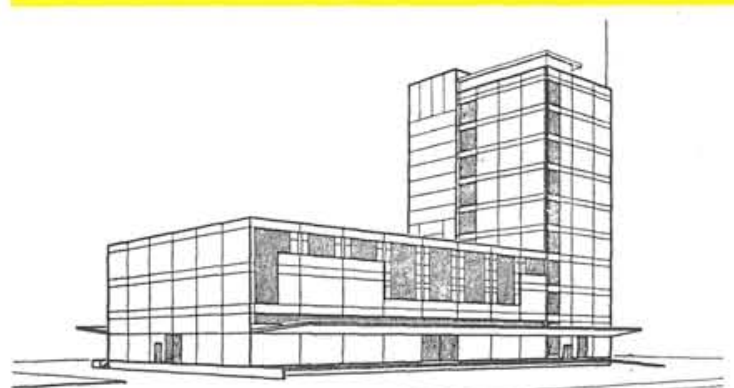

Fig. 2. Fábrica de piensos minerales UFAG. Mineral-fodder factory UFAG.

Usine pour fourrages minéraux UFAG.

\section{Fábricas \\ de piensos compuestos y piensos minerales totalmente prefabricadas}

Fábrica de piensos compuestos VLGZ Sursee (Suiza)

Propietario: Asociación de cooperativas de la Suiza central. H. Bächi, Arquit. Dipl. Luzern.

Oficina de ingeniería: J. Ganahl y A. Huonder, Ing. Dipl. Zürich.

Colaborador: P. Vajda, Ing. Dipl. Zürich.

Planificación-maquinaria: E. Hungerbühler, Ing. Unterengstringen $(\mathrm{ZH})$.

Elementos prefabricados: Maison. Element AG. Veltheim (AG).

\section{Fábrica de piensos minerales UFAG} Sursee (Suiza)

Propietario: UFAG - Sursee.

Arquitecto: J. Suter. - Sursee.

Oficina de ingeniería: J. Ganahl y A. Huonder, Ing. Dipl. Zürich.

Colaborador: P. Vajda, Ing. Dipl. Zürich.

Planificación-maquinaria: Oficina de ingeniería. E. Surbeck, Grors-Grönan/Lübeck (D).

Elementos prefabricados: Maison. Element AG. Veltheim (AG). 


\section{Descripción de los diferentes elementos prefabricados de hormigón que intervienen en la construcción de silos de cámaras múltiples}

Existen ya silos de cámaras múltiples construidos con las formas más diversas. Una mirada retrospectiva a los sistemas de prefabricación en la construcción de silos, nos muestra que, hasta ahora, ninguna solución interesante se ha realizado mediante elementos prefabricados de hormigón. Materias plásticas armaduras con fibras de vidrio han servido en la construcción de silos circulares, especialmente en los dedicados a la agricultura. Sin embargo, en silos de cámaras múltiples no circulares no encontramos, hasta la actualidad, ninguna aplicación realizada con estos materiales de forma económica.

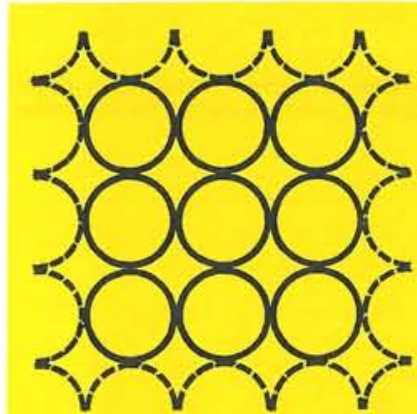

Fig. 3. Silo de cámaras múltiples circulares. Multi-compartment cylindric al silo.

Silo cylindrique à compartiments multiples.

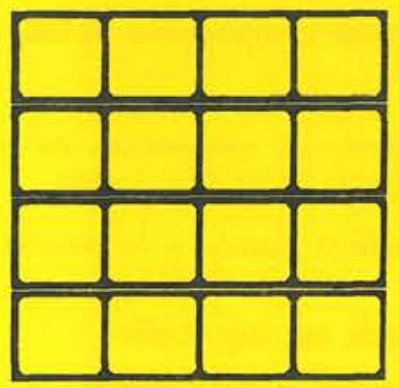

Fig. 4. Silos de cámaras múltiples con tabiques dobles en los contactos interiores. Multi-compartment silo with double wall. Silo à compartiments multi. ples avec parol double.

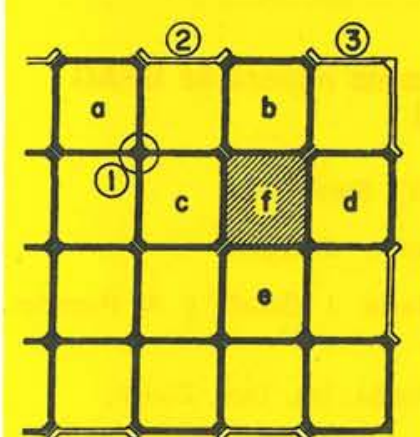

Fig. 5. Silos de cámaras múltiples con tabiques simples. Multi-compartment silo volume cell.

Cellule de volumen d'un sile à compartiments multiples.
Resumen general sobre las diferentes posibilidades de utilización de elementos prefabricados de hormigón que intervienen en la construcción de silos de cámaras múltiples

Silo de cámaras múltiples circulares. Principio de construcción: Cilindros unidos entre sí. Tamaño limitado por las posibilidades de transporte.

Ventajas. Montaje relativamente sencillo, hormigonado vertical o por procedimiento centrífugo.

Desventajas. Este procedimiento necesita una «losa maciza de absorción de las cargas estáticas». Esta losa está en general combinada con las tolvas de evacuación del silo. Los espacios comprendidos entre las cámaras circulares se pierden para el almacenaje.

Silos de cámaras múltiples con tabiques dobles en los contactos interiores

Ventajas. Superficies interiores lisas, únicamente con juntas horizontales. Las células del silo pueden ser estudiadas como sección estática resistente; de esta forma no se necesita una «losa maciza de absorción de cargas».

Desventajas. Construcción con paredes dobles, lo que hace no resulte económica desde el punto de vista de utilización de los materiales. Al ser constantes los espesores de las paredes, son inevitables desfases en las juntas entre elementos superpuestos que perjudican la salida óptima del producto almacenado (formación de puentes).

Silos de cámaras múltiples con tabiques simples

Ventajas. Los elementos celulares tienen entre ellos una mayoría de juntas horizontales.

Cuatro células forman siempre entre ellas una nueva célula (células b, c, d, e forman $\mathrm{f}$ ). (Ver figura contigua).

Desventajas. La anchura de las células viene limitada por el transporte. Las uniones entre las diferentes células (punto 1) tienen que ser efectuadas mediante tornillos de alta resistencia, originando algunas dificultades. Las juntas horizontales de transición no pueden realizarse de una forma irreprochable: la causa es la presencia de tolerancias de montaje. En los puntos 2 y 3 hay que realizar elementos de una sola pared y elementos de ángulo. Los esfuerzos en las uniones verticales siguen siendo poco conocidos y muy aproximados. Esta carencia puede ser sensiblemente mejorada mediante el nuevo anclaje de tracción descrito más adelante (ver figura 16).

Este tipo de silo necesita, al igual que los silos de cámaras circulares, una "losa maciza de absorción de las cargas" combinada con las tolvas de salida. 
EH - Silo de cámaras múltiples con tabiques simples (sistema: Element AG. Veltheim, Ing. Huonder, Zürich, patente registrada)

El sistema descrito a continuación se ha empleado por primera vez en Sursee (Suiza) en la construcción de dos grandes silos.

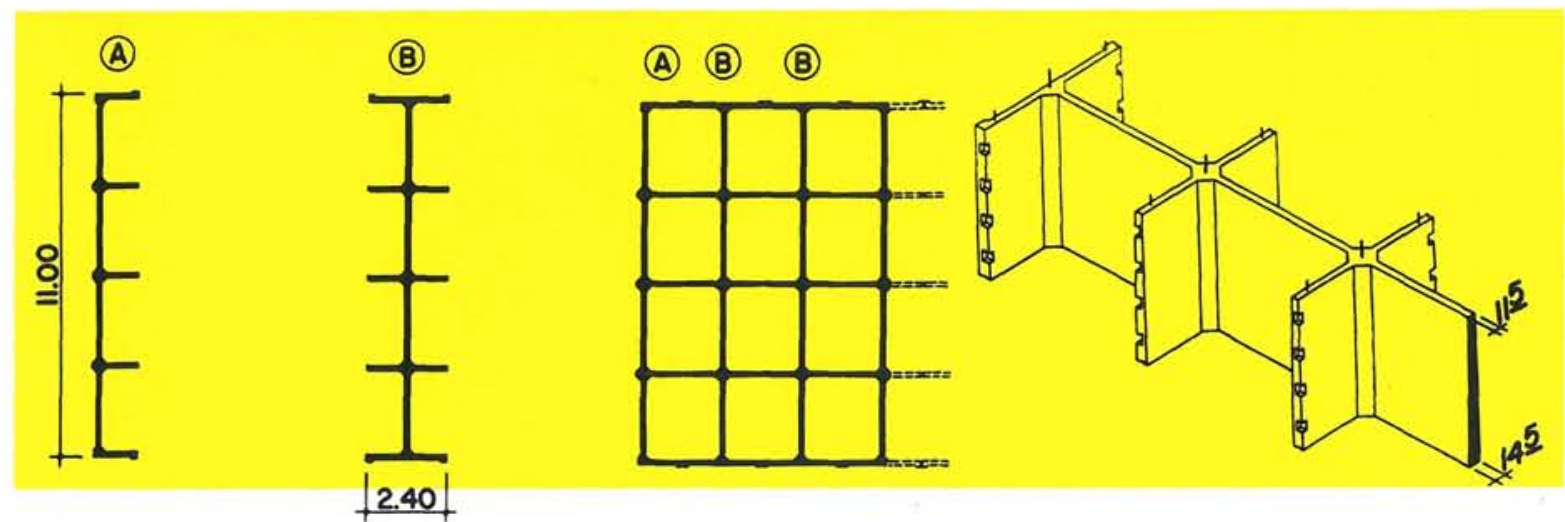

Fig. 6. Célula extremo.

End cell.

Cellule d'extrémité.
Fig. 7. Unidad base de las células.

Basic-cell unit.

Unité de cellule de base.
Elementos de descarga prefabricados de hormigón para silos

Fig. 9 a. Descarga: Sistema para piensos compuestos VLGZ Element outles VLGZ.

Elément de décharge VLGZ.

Fig. 9 b. Descarga: Sistema para piensos minerales UFAG. Element outlets UFAG.

Elément de décharge UFAG.

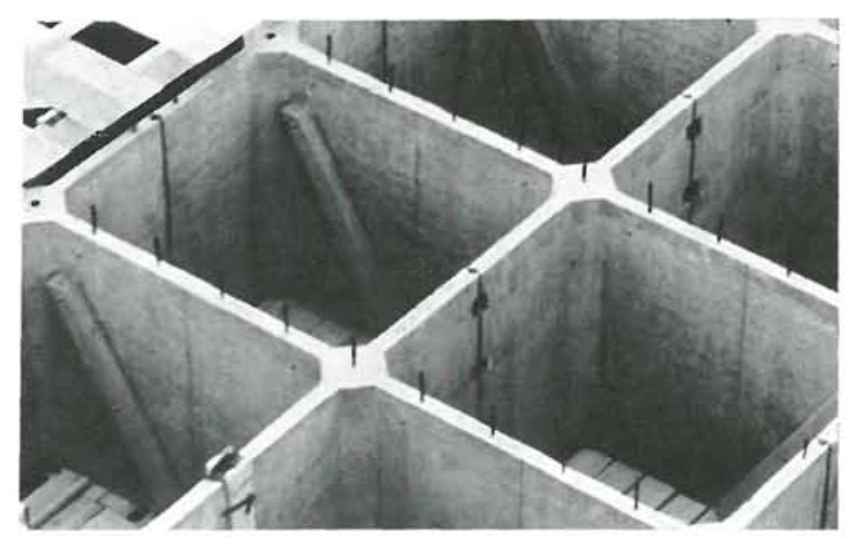

Fig. 10. EH - Silo de cámaras múltiples durante su montaje. EH - Assembled silo compartments.

Fig. 10 a. Detalle de un EH - silo de cámaras múltiples. Detail of EH silo compartment. Détail d'un compartiment de silo EH
Fig. 8. Silo de cámaras múltiples EH.

EH multi - compartment

silo.

Silo à compartiments

multiples $\mathrm{EH}$
Fig. 9. Unidad de célula de base: perspectiva. Basic-cell unit: perspec. tive drawing.

Unité de cellule de ba. se: perspective.
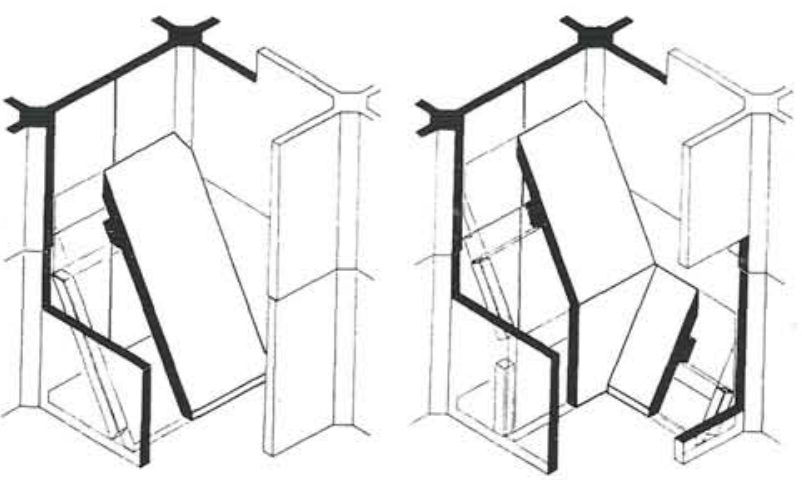

Fotor LEO MOSER

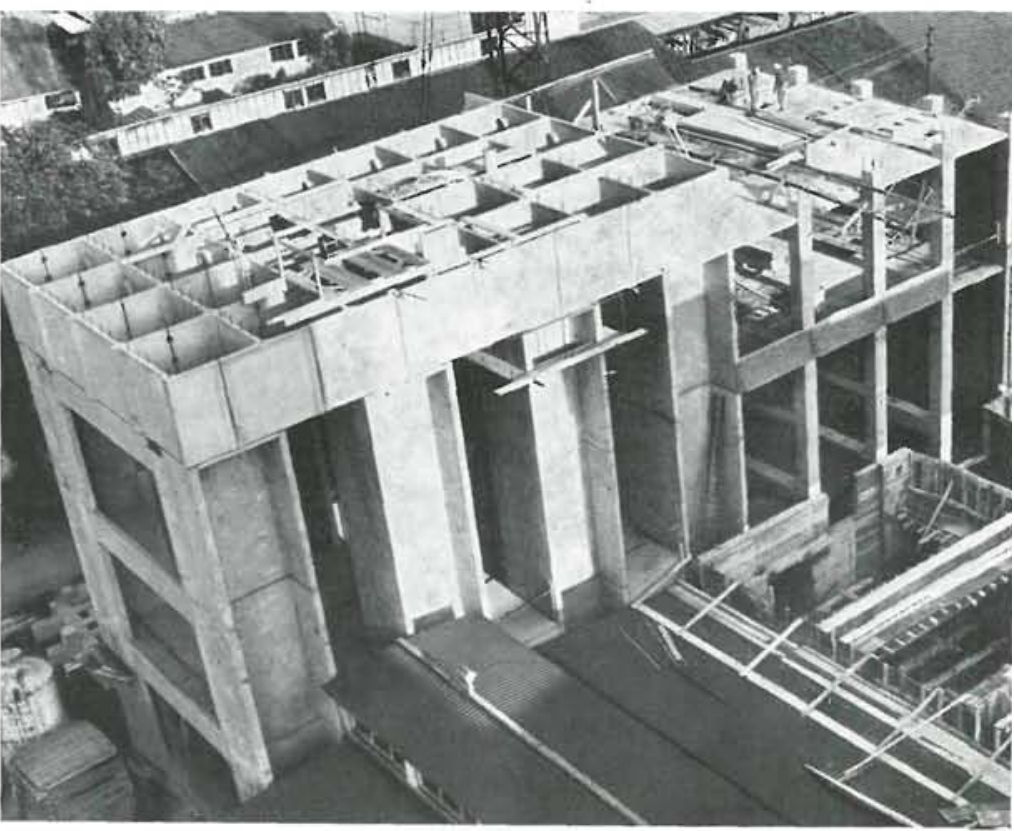




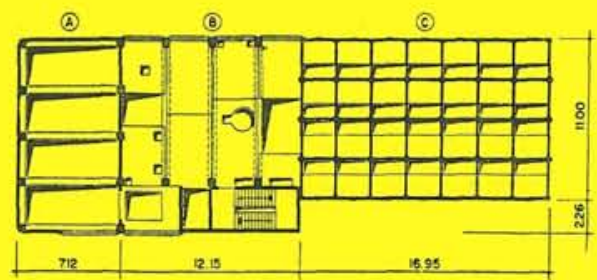

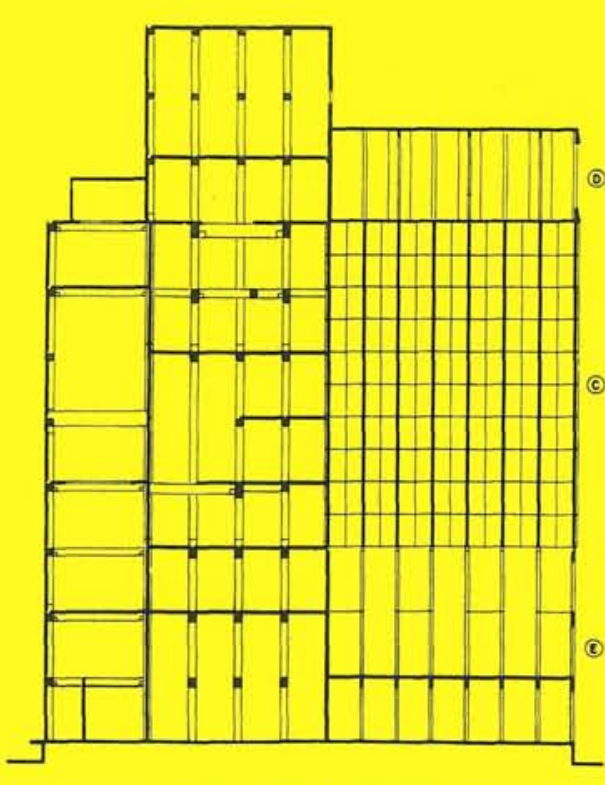

Fig. 11. Planta y secciones: Construcción para piensos compuestos VLGZ.

Ground-plan and section: VLGZ silo. Plan et coupe: silo VLGZ.

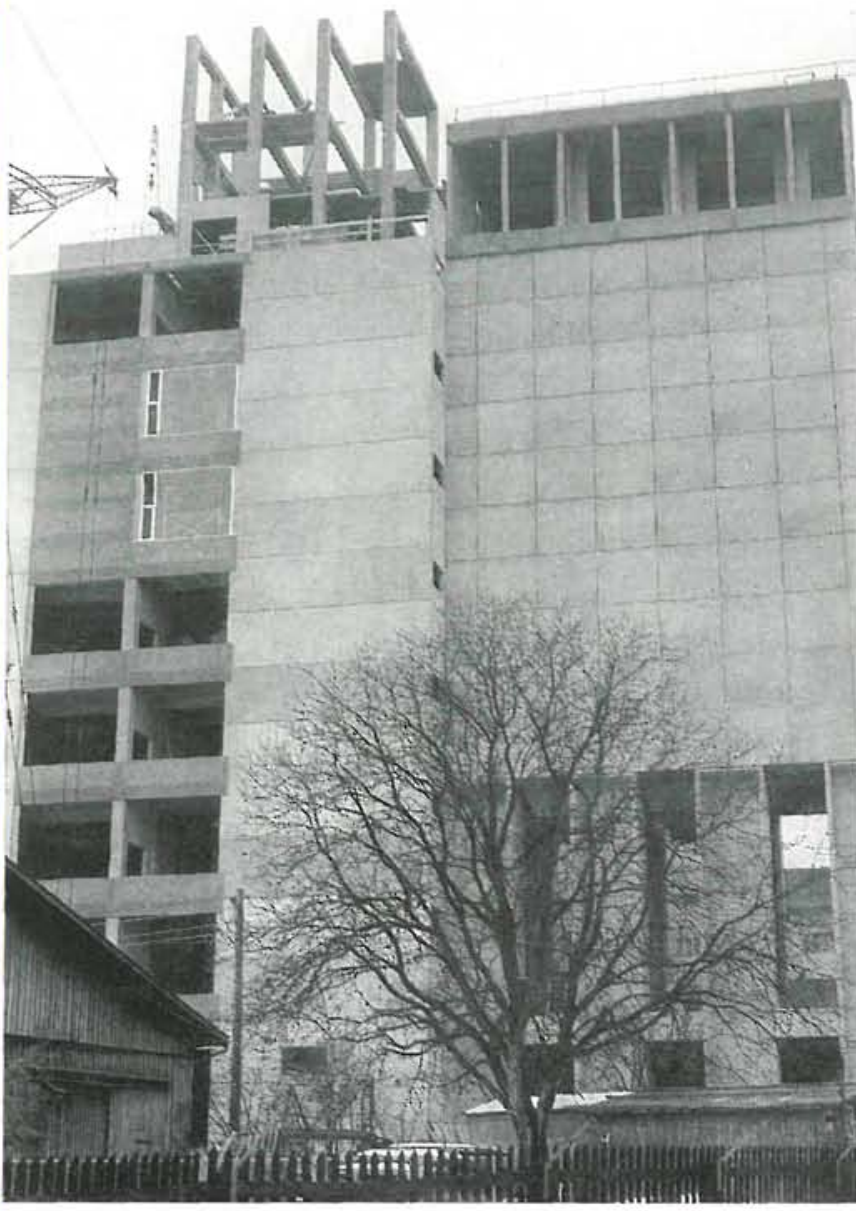

Fotor IEO MOSER

Fig. 12. Vista del silo de piensos compuestos VLGZ. Elevation of mixed-fodder factory VLGZ. Vue en élévation: usine pour fourrages mélangés VLGZ.

\section{Técnica del montaje del silo EH de cámaras múltiples}

Los elementos de los extremos y del centro se fabrican con un solo encofrado metálico.

Al proyectar, las dimensiones de los elementos de las células se establecen en función de las posibilidades de transporte. Si se prevé una instalación de fabricación en las proximidades de la obra, los elementos de las células pueden ser proyectados libremente.

La altura de los elementos de las células se determina teniendo en cuenta, por una parte, las posibilidades de transporte y, por otra, la capacidad de los medios de elevación de que se dispone. En la construcción de estas obras, el peso de un elemento medio ascendía a unas $18 \mathrm{t}$ aproximadamente.

La forma cónica de las paredes de las células (patente registrada), de una anchura superior de $11,5 \mathrm{~cm}$ y una anchura inferior de $14,5 \mathrm{~cm}$, permite una salida óptima del material almacenado en el silo. Esta forma cónica de las paredes (que origina una estructura de paredes imbricadas) evita los decalajes entre paredes que se producen en las juntas horizontales, no existiendo ya, por tanto, el riesgo de formación de puentes en el almacenaje.

La superficie lisa de las paredes en el interior de las células se obtiene de una forma impecable en una sola operación, gracias a la utilización de moldes metálicos de encofrado. Un tratamiento anterior de estas superficies resulta superfluo.

Las paredes principales del silo se estudian como secciones estáticas resistentes; de esta forma se tiene la ventaja de poder prescindir de una "losa maciza de absorción de cargas n.

Se ha utilizado con éxito una unión que garantiza una adherencia perfecta en las juntas verticales de las paredes, permitiendo igualmente ejercer una presión en dichas juntas (unión mediante anclaje de tracción, patente registrada). 

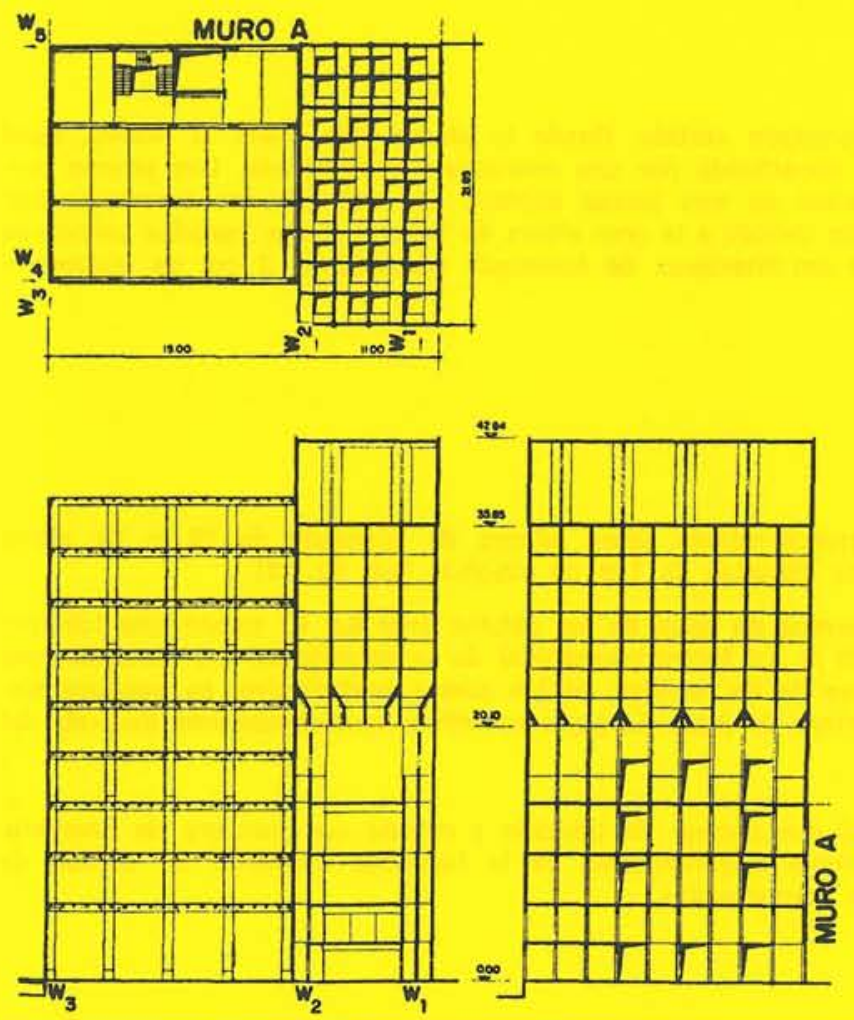

Fig. 13. Planta y secciones: Silo UFAG para piensos minerales.

Ground-plan section: UFAG silo.

Plan en coupe: silo UFAG.

Los silos EH de cámaras múltiples reposan sobre pilares en forma de $\mathrm{H}$. Estos pilares se pueden cerrar con paredes laterales y servir como silos de control de almacenaje.

\section{Construcción para piensos minerales UFAG en Sursee}

Presenta tres partes distintas de la obra:

- El depósito.

- La torre.

- El silo.

\section{Características del depósito}

El depósito está simplemente indicado en planta y en sección (ver fig. 13). Su superficie es de $48 \times 30 \mathrm{~m}$. El sótano es de hormigón vertido. La planta baja, la 1.' y la 2.: están constituidas por elementos prefabricados. La $10^{\circ}$ y la 2. planta están constituidas por una estructura igualmente prefabricada de hormigón que soporta toda la carga de la obra. De esta estructura están suspendidas unas losas nervadas de hormigón pretensado (disposición en lecho de la armadura) de $6 \mathrm{~m}$ de luz y $1.500 \mathrm{kp} / \mathrm{cm}^{2}$ de sobrecarga.

Las losas de techumbre fueron realizadas en construcción tipo sandwich. Los durmientes transversales de hormigón colado, calculados como vigas simples, van armados normalmente y tienen $9 \mathrm{~m}$ de luz. Los pilares prefabricados de hormigón están empotrados y tienen tres ménsulas cuadradas superpuestas. 


\section{Características de la torre}

Superficie en planta, $19 \mathrm{~m} \times 19 \mathrm{~m}$. Sótano de hormigón vertido. Desde la planta baja hasta la octava, igual que en el depósito, la estructura resistente está constituida por una estructura prefabricada. Los pilares prefabricados, de hormigón, de $38 \mathrm{~m}$ de altura, se montan en tres piezas sueltas. Las tres paredes exteriores han sido concebidas para resistir a la presión del viento debido a la gran altura de la torre. Estas paredes exteriores son losas tipo sandwich de $20 \mathrm{~cm}$ de espesor $(10 \mathrm{~cm}$ interiores de hormigón sustentante, $3 \mathrm{~cm}$ de aislante y $7 \mathrm{~cm}$ exteriores de hormigón visto con estrías).

\section{Características del silo}

Superficie en planta, $22 \times 11 \mathrm{~m}$. Altura, $42 \mathrm{~m}$.

Sótano, de hormigón vertido in situ. El silo prefabricado reposa sobre pilares de hormigón de $20 \mathrm{~m}$ de altura en forma de $\mathrm{H}$. Estos pilares constan de cinco partes distintas de $4 \mathrm{~m}$ de longitud (ver fig. 13).

Altura del silo propiamente dicho, $16 \mathrm{~m}$. Los elementos de base de las células (ver fig. 9) tienen una longitud de $11 \mathrm{~m}$, una anchura de $2,20 \mathrm{~m}$ y una altura de $2,25 \mathrm{~m}$. La forma trapezoidal de la sección de las paredes pasa de 11,5 a $14,5 \mathrm{~cm}$ de anchura. La unión de las partes de las células en las juntas horizontales se asegura mediante unas armaduras de empalme y $2 \mathrm{~cm}$ de mortero de junta. La junta se rellena cuidadosamente después del montaje.

Juntas verticales de las paredes. $1,5 \mathrm{~cm}$ de espesor con anclaje de tracción y relleno con mortero de cemento. Las juntas de fachada se aseguran doblemente contra la penetración de la humedad mediante un cordón de caucho flexible de Neopreno y una masilla de dos componentes.

\section{Bases del cálculo estático}

La absorción de las cargas verticales, así como el peso propio y la sobrecarga del depósito y de la torre, se ha asegurado mediante el sistema resistente descrito anteriormente. En el depósito todas las fuerzas verticales y horizontales se han absorbido por los pilares exclusivamente. En la torre, las paredes exteriores se utilizan como contraviento. Soportan verticalmente el peso propio y las sobrecargas. Las cargas verticales son tan grandes con relación al peso propio que la resultante de las solicitaciones origina siempre tensiones de compresión en todas las secciones horizontales de las paredes.

El empuje del viento ha sido absorbido como sigue (ver fig. 13): en la dirección $\mathbf{X}$ mediante 3 contravientos, $\mathbf{W}_{1}$ y $W_{2}$, que están constituidos por los pilares en $\mathrm{H}$ de los silos y de las paredes, y $\mathbf{W}_{3}$ formado por la pared exterior resistente de la torre. El empuje del viento en la dirección $\mathbf{Y}$ se absorbe con las paredes exteriores $\mathrm{W}_{4}$ y $\mathrm{W}_{5}$.

El conjunto del empuje del viento $\mathbf{W}_{\mathrm{x}} \mathrm{y} \mathbf{W}_{\mathrm{y}}$ se reparte en los contravientos en función de la rigidez de éstos.

Las tensiones en los bordes debidas al viento y a las cargas verticales (peso propio y sobrecarga) se sitúan entre 40 y $60 \mathrm{kp} / \mathrm{cm}^{2}$. Las fuerzas de cizallamiento en las juntas verticales de las paredes son absorbidas por un mortero de cemento y por las ménsulas de los pilares. De esta forma se puede prescindir de armadura para el esfuerzo cortante y de la armadura de empalme. Los contravientos son muy rígidos, siendo solamente de 2 a $4 \mathrm{~mm}$ la flecha horizontal para $38 \mathrm{~m}$ de altura.

Solicitaciones en el silo. Las 36 células del silo se llenan con pienso mineral (a base de sal) cuyo peso es de $1,4 \mathrm{t} / \mathrm{m}^{3}$ y tiene un ángulo de rozamiento interno de $\varrho=40^{\circ}$.

Las cargas para el silo corresponden a los datos de las normas DIN 1055 , página 6.

El empuje de llenado alcanza con $5 \mathrm{~m}$ de profundidad, su reparto máximo.

\begin{tabular}{|c|c|c|}
\hline DESCRIPCION DE LAS CARGAS & CON LLENADO & VACIO \\
\hline Verticales sobre el suelo: máx. $\mathbf{P}_{\mathrm{v}} \ldots \ldots \ldots \ldots \ldots \ldots$ & $3,04 \mathrm{Mp} / \mathrm{m}^{2}$ & $1,96 \mathrm{Mp} / \mathrm{m}^{2}$ \\
\hline Horizontales sobre las paredes: máx. $\mathbf{P}_{\mathrm{h}} \ldots \ldots \ldots \ldots \ldots$ & $1,52 \mathrm{Mp} / \mathrm{m}^{2}$ & $1,96 \mathrm{Mp} / \mathrm{m}^{2}$ \\
\hline Rozamiento vertical en las paredes: máx. $\mathbf{P}_{\mathrm{w}} \ldots \ldots \ldots \ldots$ & $0,87 \mathrm{Mp} / \mathrm{m}^{2}$ & $0,87 \mathrm{Mp} / \mathrm{m}^{2}$ \\
\hline
\end{tabular}



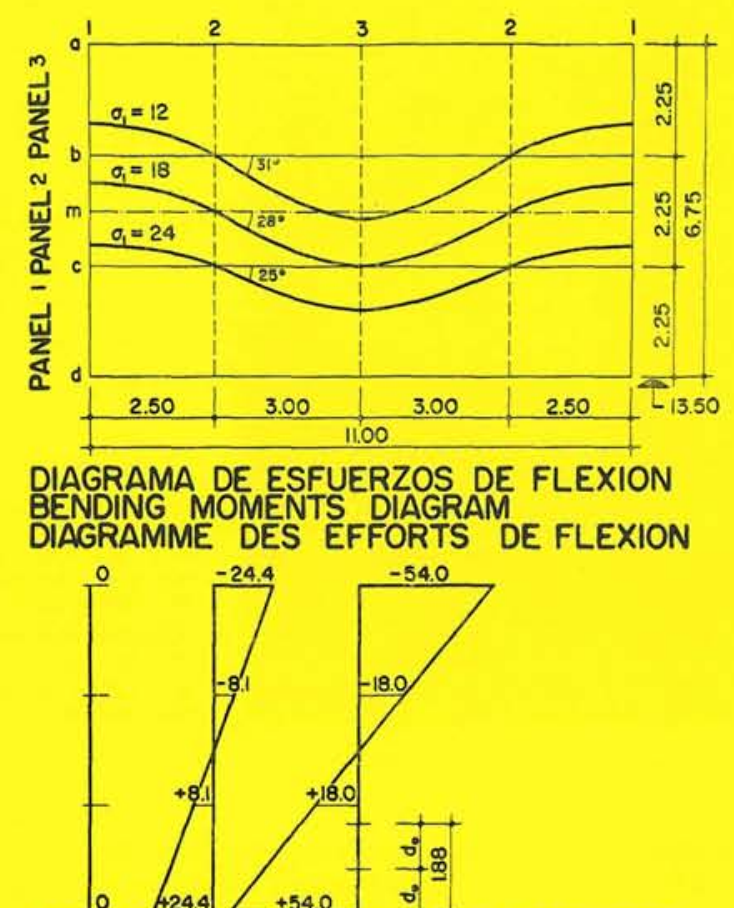

IAGRAMA DE ESFUERZOS CORTANTES

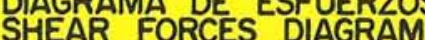

DIAGRAMME DES EFFORTS TRANCHANTS

$\tau_{\text {zut. }}=1.7 \sqrt{600}=38>33$
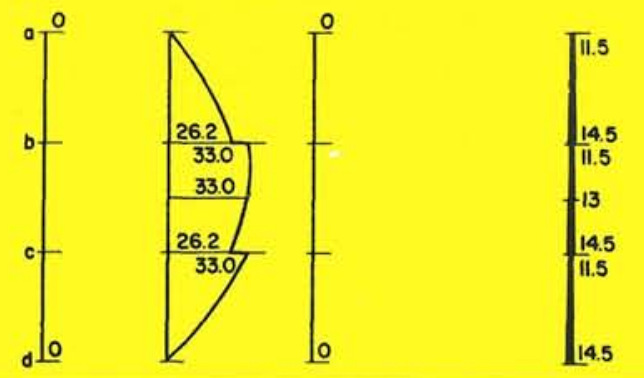

Fig. 14. Trayectorias de las tensiones Stress trajectories.

Trajectoires de contraintes.

\section{Trayectorias de las tensiones en las paredes resistentes del silo}

En el dimensionamiento de las paredes de las célu. las del silo se ha considerado un empuje horizontal máximo de $1,96 \mathrm{Mp} / \mathrm{m}^{2}$.

Las paredes de las células se han calculado como un marco con dos articulaciones y una presión uniformemente repartida en su interior.

El marco de dos articulaciones es isostático a causa de la simetría doble.

Las articulaciones del marco no soportan más que fuerzas centradas.

Estas fuerzas centradas se absorben mediante el nuevo sistema de anclaje de tracción (patente registrada, ver fig. 16).

La fuerza máxima de tracción se eleva a $5,05 \mathrm{Mp} / \mathrm{m}$, es decir, 2,85 Mp por anclaje de tracción en el caso del silo UFAG.

En el caso del silo VLGZ este valor es de 4,04 $\mathrm{Mp} / \mathrm{m}$, es decir, 2,30 Mp/anclaje de tracción. Ile. nado el silo con producto de $0,8 \mathrm{t} / \mathrm{m}^{3}$ y ángulo de rozamiento interno $\varrho=30^{\circ}$.

Las paredes del silo están solicitadas a flexión y tracción. Una armadura de malla se ha colocado a cada lado de las paredes. El silo reposa sobre pilares en forma de $\mathrm{H}$ mediante tres paredes inferiores prefabricadas. Estos pilares están cargados verticalmente con su propio peso y con el material almacenado. La carga soportada oscila entre 800 y $1.000 \mathrm{Mp} /$ pilar. Para el cálculo de la presión del viento se ha admitido un empotramiento perfecto en los dos extremos de los pilares. La resistencia al esfuerzo cortante y a los esfuerzos horizontales en las juntas de las células b y c (ver fig. 14) se asegura con un mortero adherente a base de resina epoxi.

\section{Mortero a base de resina sintética para uniones de elementos prefabricados de hormigón}

Presentación del problema. Cuando existe una temperatura baja (entre $+3^{\circ} \mathrm{y}+10^{\circ} \mathrm{C}$ ) y un tiempo de endurecimiento muy corto ( 6 a 18 horas), la unión entre elementos prefabricados se debe realizar de manera que se soporten los esfuerzos estáticos de una forma duradera con el tiempo. El esfuerzo cortante existente se debe absorber en toda la superficie de la junta horizontal.

La solución. En obra el problema se resuelve de forma práctica y razonable con la utilización de un mortero a base de resina sintética.

Todos los elementos del silo que deben ser pegados tienen preparada por adelantado sus superficies.

La pasta de cemento aparece en la superficie durante el hormigonado del elemento, formando una película que es necesario cepillar (limpieza con chorro de arena) antes de encolar. En la obra se monta un elemento sin cola, 


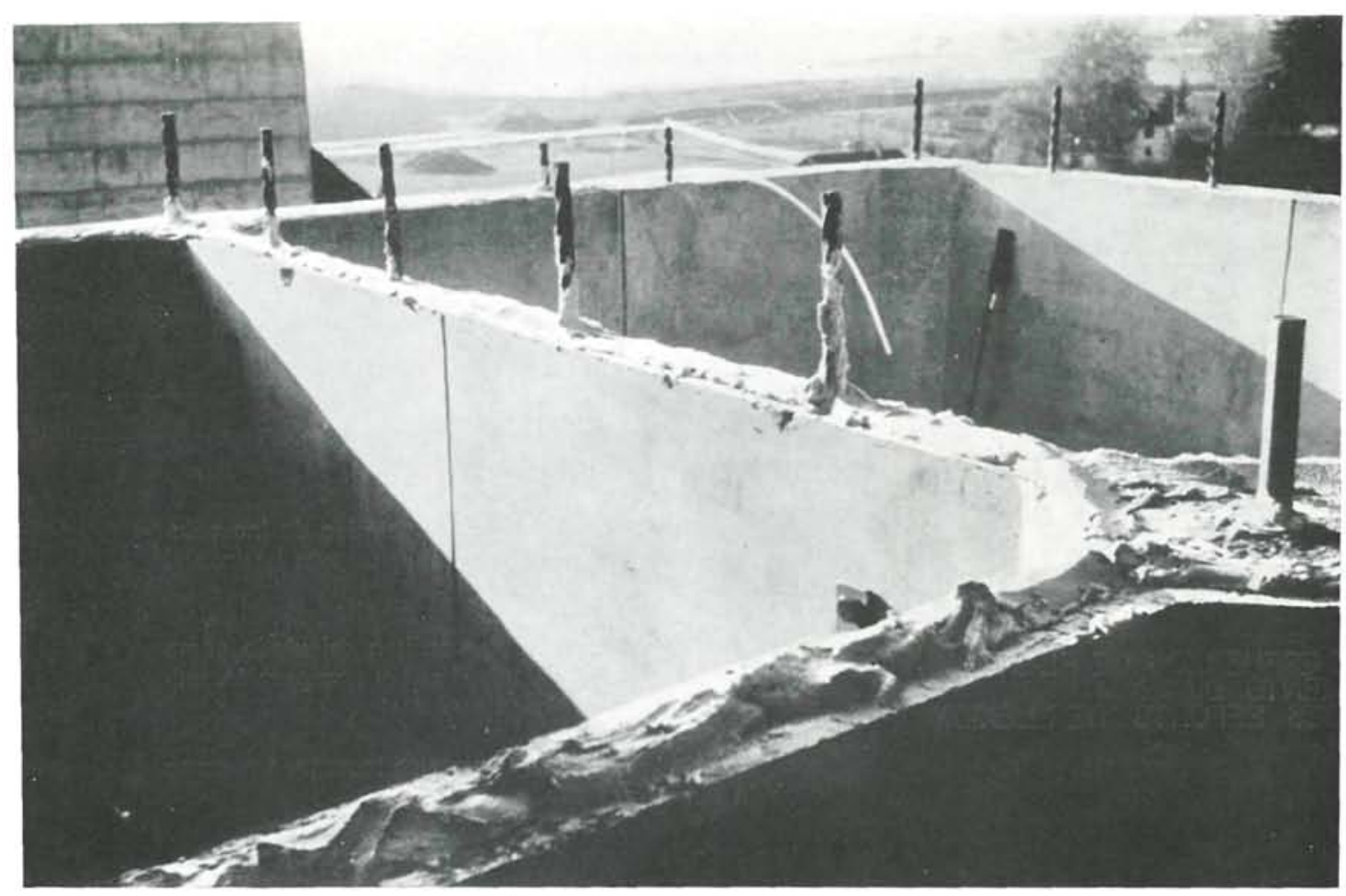

Fig. 15. Aplicación del mortero de eposoportan esfuerzos de cizallamiento.

Application of epoxi mortar.

Application de mor. tier époxyde.

sobre separadores de plástico o metálicos, se le retira de nuevo y se coloca el mortero adherente de epoxi en forma de cubierta. De esta forma en el montaje definitivo del elemento superior el mortero adherente se extiende sin dejar huecos (ver fig. 15).

Se coloca el mortero de epoxi en forma de triángulo en la superficie de contacto del elemento. Esta manera de proceder resulta económica e impide toda formación de burbujas de aire. Unos tacos de separación y unas arandelas evitan un aplastamiento completo del mortero y aseguran al mismo tiempo la precisión en la colocación del siguiente elemento.

Al igual que en la técnica del pretensado, los conductos se realizan con chapa de acero ondulada. La longitud de anclaje es como mínimo de $12 \varnothing$ para aceros bien trefilados, siendo la holgura en el conducto de $2 \mathrm{~cm}$ respecto al diámetro de la armadura de espera.

A causa del peligro de ensuciamiento de los conductos y a fin de lograr una colocación sencilla de los elementos, es ventajoso que las armaduras de empalme estén dirigidas hacia arriba y los conductos hacia abajo.

Cada conducto debe tener una abertura de llenado con salida lateral por la que se pueda inyectar el mortero de poliéster líquido sin que haya necesidad de hacer aberturas suplementarias para la evacuación del aire.

La unión por anclaje de tracción (Sistema Ing. Huonder, patente registrada).

Los siguientes datos son los del silo VLGZ.

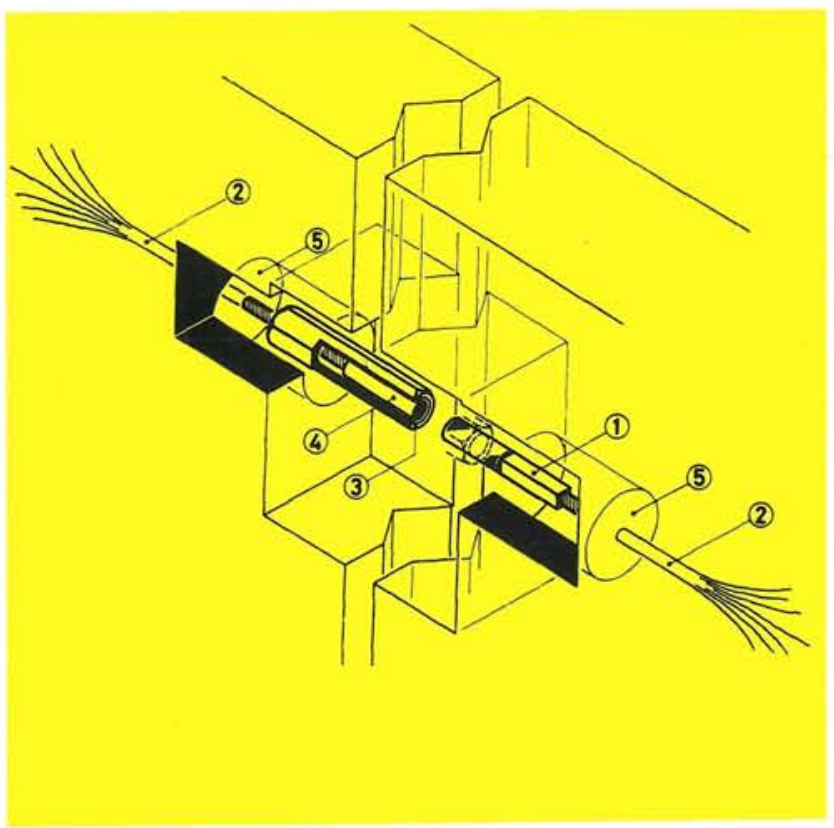

Fig. 16. Anclaje.

1. Casquillo de apretado fileteado.

2. Cable metálico $\varnothing 10$ ó $12 \mathrm{~mm}$

3. Tuerca larga M 20

. Casquillo interior de apretado sin roscar.

Cavidad para el cable hecha con styropor para dejar una holgura de $2 \mathrm{~cm}$ aproximadamente al cable.

Tie rods.

1. Threaded press sleeve

2. Wire rope, diam. 10 or $12 \mathrm{~mm}$.

3. Long nut $\mathrm{M} 20$.

4. Inner press sleeve, unthreaded.

5. Concrete recess (syropor), so that approx. $2 \mathrm{~cm}$ of wire rope are flexible.

Tirants.

1. Douille pressée filetée

2. Câble métallique $\varnothing 10$ ou $12 \mathrm{~mm}$

3. Ecrou long M 20 .

4. Douille pressée Juen, non filetée. Evidement de béton (styropor), pour
du câble métallique soient flexibles. 
Descripción técnica. Para absorber de una manera óptima las tracciones en las juntas verticales (silo VLGZ, UFAG) los nuevos anclajes de tracción se montan a una distancia de $62 \mathrm{~cm}$ aproximadamente (ver fig. 16).

El anclaje de tracción se compone de las siguientes partes:

Dos cables metálicos de $10 \mathrm{~mm}$ de diámetro y $60 \mathrm{~cm}$ de longitud. Uno de los extremos de un cable está provisto de un casquillo metálico apretado. Envolviendo este casquillo se encuentra una tuerca larga M 20 con roscado interior. El otro extremo del otro cable va provisto de un casquillo fileteado $\mathrm{M} 20$.

Los dos cables están colocados en el eje del elemento de tal manera que queda siempre un juego de $2 \mathrm{~cm}$ al cable en su cavidad. Los extremos de los cables están destrenzados y hormigonados en la pared. En obra, después del montaje de los elementos, la tuerca larga se enrosca sobre la parte fileteada del casquillo del otro cable al mismo tiempo que se efectúa el relleno de las juntas. Este procedimiento asegura una perfecta unión a tracción o a compresión.

Al mismo tiempo el anclaje de tracción presenta diferentes ventajas en este tipo de unión. Estas son las siguientes:

Con relación a las uniones realizadas con armaduras de espera:

Los encofrados de las partes frontales son sencillos.

El laborioso hormigonado de las juntas ya no se realiza.

La experiencia demuestra que tales uniones (anclajes de tracción + mortero) no se fisuran.

Con relación a las uniones soldadas:

Poca sensibilidad en las tolerancias.

Realización rápida.

Gran seguridad.

Los elementos prefabricados pueden, incluso después de su colocación, experimentar reajustes gracias al anclaje de tracción.

El ajuste de los elementos necesita poco esfuerzo.

El mortero de las juntas puede ser pretensado.

El anclaje de tracción, incluida la colocación. cuesta aproximadamente 26 francos por pieza.

Cualquier otro sistema de anclaje es más caro.

\section{Resultado de las investigaciones sobre la tracción admisible}

Tracción y compresión en flexión de 2 elementos de pared de hormigón unidos por 4 anclajes de tracción.

Los ensayos de rotura y las investigaciones sobre los cables y los casquillos de apretado, han demostrado que la adherencia del casquillo al cable es mayor que la resistencia a tracción de este último.

Al hormigonar los cables en los elementos prefa. bricados, la forma cónica obtenida destrenzando el cable ofrece una mayor resistencia al arranque que la resistencia a tracción del cable.

En todos los casos de carga, los ensayos han demostrado que la resistencia a tracción del cable era determinante.

Resistencia a rotura del cable $\varnothing 10 \mathrm{~mm}=8.000$ kilopondios $/ \mathrm{cm}^{2}$.

Carga de rotura: 6,3 Mp/anclaje.

Carga admisible con un coeficiente de seguridad $3 \mathbf{P}_{\mathrm{adm}}=6,3 / 2=2,1 \mathrm{Mp} /$ anclaje.

Fig. 17. Ensayos a tracción por el servicio federal de en. sayo de materiales (EMPA), de Zürich.

Tensile test EMPA.

Essai de traction EMPA.

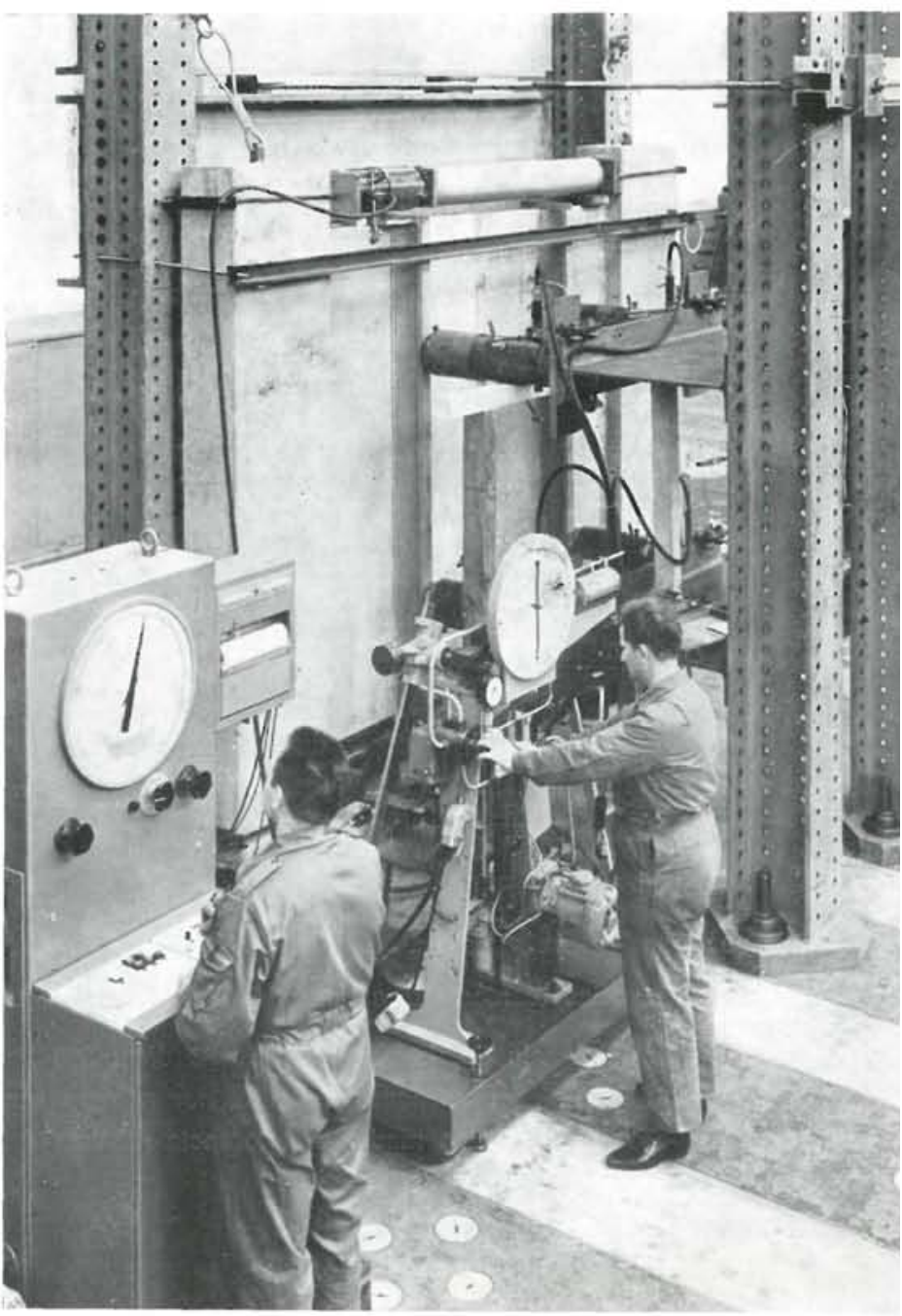


Para estudiar las uniones propiamente dichas se efectuaron dos ensayos con elementos de pared de hormigón armado por el Servicio Federal de Ensayo de Materiales (EMPA) en Zürich (Informe EMPA núm. 68.005).

Altura de los elementos de pared: $2,23 \mathrm{~m}$; número de anclajes de tracción para unión de las paredes: 4/pieza (ver fig. 17).

A causa de la deteriorización de un anclaje de tracción, únicamente se tuvieron en cuenta los resultados de un ensayo.

La carga de rotura ascendió a $27 \mathrm{Mp} /$ pared, es decir, 6,7 Mp/anclaje para la tracción sola. El resultado fue algo superior al de los ensayos del anclaje aislado.

Otros ensayos en el centro EMPA han demostrado:

a) Que el anclaje de tracción ha resistido 50 alternaciones de carga $\left(\mathbf{P}=2 / 3 \quad \mathbf{P}_{\text {rotura }}=2 \times \mathbf{P}_{\text {adm }}\right)$ sin que aparezcan deformaciones.

b) Que la junta vertical puede soportar simultáneamente al esfuerzo de tracción un momento flector de hasta $\mathbf{M}=0,85 \mathrm{Mp} \cdot \mathrm{m} / \mathrm{m}$. Este momento corresponde más o menos al momento medido en el ángulo de las paredes del silo. Así, pues, esta unión ofrece una seguridad suplementaria con relación al sistema de mano con dos articulaciones.

\section{Comprobaciones durante el montaje del silo VLGZ en Sursee}

Las uniones realizadas con anclaje de tracción han resultado muy ventajosas. Todos los anclajes de tracción han sido tesados sin dificultad. Además de las paredes, otras partes del silo han podido ser unidas mediante anclajes de tracción, como, por ejemplo, la caja de la escalera y del ascensor. En el caso del silo UFAG, se aumentó el diámetro del cable del anclaje a $12 \mathrm{~mm}$ a causa de una mayor presión horizontal sobre las paredes. Con ello la carga admisible se elevó a 2,85 Mp/anclaje.

\section{Construcción del encofrado, fabricación de los elementos y montaje de las células del silo}

\section{Nota preliminar}

Fue en el curso de una reunión de un grupo de trabajo, integrado por el ingeniero y la empresa de prefabricación, cuando se examinó, sobre la base de un proyecto del arquitecto, la posibilidad de construir el silo para piensos compuestos VLGZ totalmente con elementos prefabricados de hormigón. El resultado del estudio mostró que, a pesar de las exigencias muy diversas y de la importante altura de $53 \mathrm{~m}$ de la construcción, la prefabricación presentaba ventajas ciertas:

a) Las exigencias estáticas y de construcción fueron relativamente fáciles de resolver, según los datos arriba indicados, en el silo de cámaras múltiples.

b) Una comparación de gastos, efectuada por el arquitecto, entre la construcción tradicional de hormigón vertido in situ y la de elementos prefabricados, mostró como ventajosa la solución con elementos prefabricados.

c) La garantía del plazo de construcción y la rápida ejecución de las obras fueron de gran importancia para el contratista. (Un año suplementario de construcción ahorrado).

d) La finura de las superficies interiores de las células, obtenida por primera vez en una obra semejante, redujo sensiblemente el rozamiento del pienso con las paredes.

La presencia de un desfase negativo en las juntas horizontales debido a la forma trapezoidal de los elementos, previene contra la formación de puentes en el pienso.

Fue por estas diversas razones por lo que el contratista se decidió por una construcción a base de elementos prefabricados para toda la parte no subterránea.

Los temas que a continuación se desarrollan se refieren a la fabricación del encofrado, construcción y montaje de los elementos de las células del silo que, en su género, representa un trabajo pionero en el sector de la construcción prefabricada.

Las exigencias técnicas de estas unidades de células fueron las siguientes:

a) Resistencia del hormigón a los 28 días: $500 \mathrm{kp} / \mathrm{cm}^{2}$.

b) Superficies muy lisas con el menor número posible de poros.

c) Exactitud de las medidas: tolerancia máxima $\pm 5 \mathrm{~mm}$. 
Fig. 18. Elemento de silo, desencofrado. Silo compartment, stripped. Elément de silo, décoffré.

Fig. 19. Vista, desde arriba, del encofrado del silo. Inside view of silo formwork. Vue intérieure du coffrage de silo.

\section{Encofrado de las unidades de las células}

El elemento de silo desencofrado. Bien visible, el elemento de acero en la parte inferior del encofrado. También se observa la posibilidad de fijación del molde.

Los altos requisitos arriba citados pudieron ser cumplidos gracias al extremado cuidado tenido en la ejecución del molde.

Como material de encofrado no se consideraron más que los moldes metálicos.

Estos se componen de diferentes partes: 8 partes de molde en forma de $U$ colocadas verticalmente, con las dimensiones de una semicélula, con dos superficies para el encofrado frontal, formando el conjunto el negativo del elemento prefabricado.

En su parte inferior, las paredes están rígidamente fijadas por un elemento metálico nivelado y hormigonado (ver figura 18)

Para asegurar la inmovilidad de la parte superior, se mon taron 5 pares de pilares de hormigón empotrados en la plataforma de apoyo, en prolongación de las paredes trans. versales del elemento. Cada par de cabezas de pilar constituye el apoyo para un marco de fijación, el cual a su vez mantiene la parte superior de la pared en la posición y con la precisión deseada. Para las mediciones se recurrió a un topógrafo.

A fin de que los encofrados en forma de $U$, de superficie relativamente grande y sección rectangular, puedan ser desencofrados con facilidad, se ha construido, en su lado mayor, una charnela vertical.

Vista desde arriba. Los moldes en U están cerrados. En la prolongación de las paredes transversales se aprecian los pilares de hormigón sobre las cabezas de los cuales se coloca el marco de fijación.

Con una tolerancia de $3 \mathrm{~mm}$ en la charnela, no existen dificultades durante el desencofrado por cerramiento de los moldes en $\mathrm{U}$.

Alrededor de esta articulación, las dos partes del molde. que están montadas sobre unas pequeñas ruedas, pueden abrirse o cerrarse cómodamente para desencofrar o encofrar el elemento (ver fig. 19).
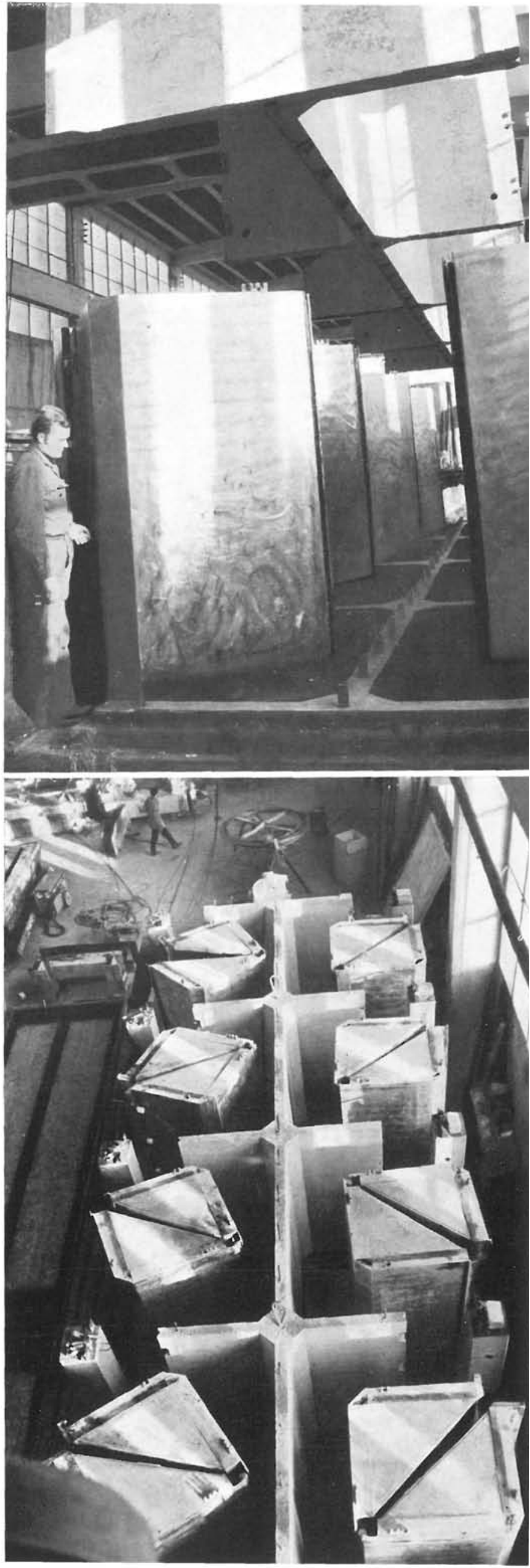


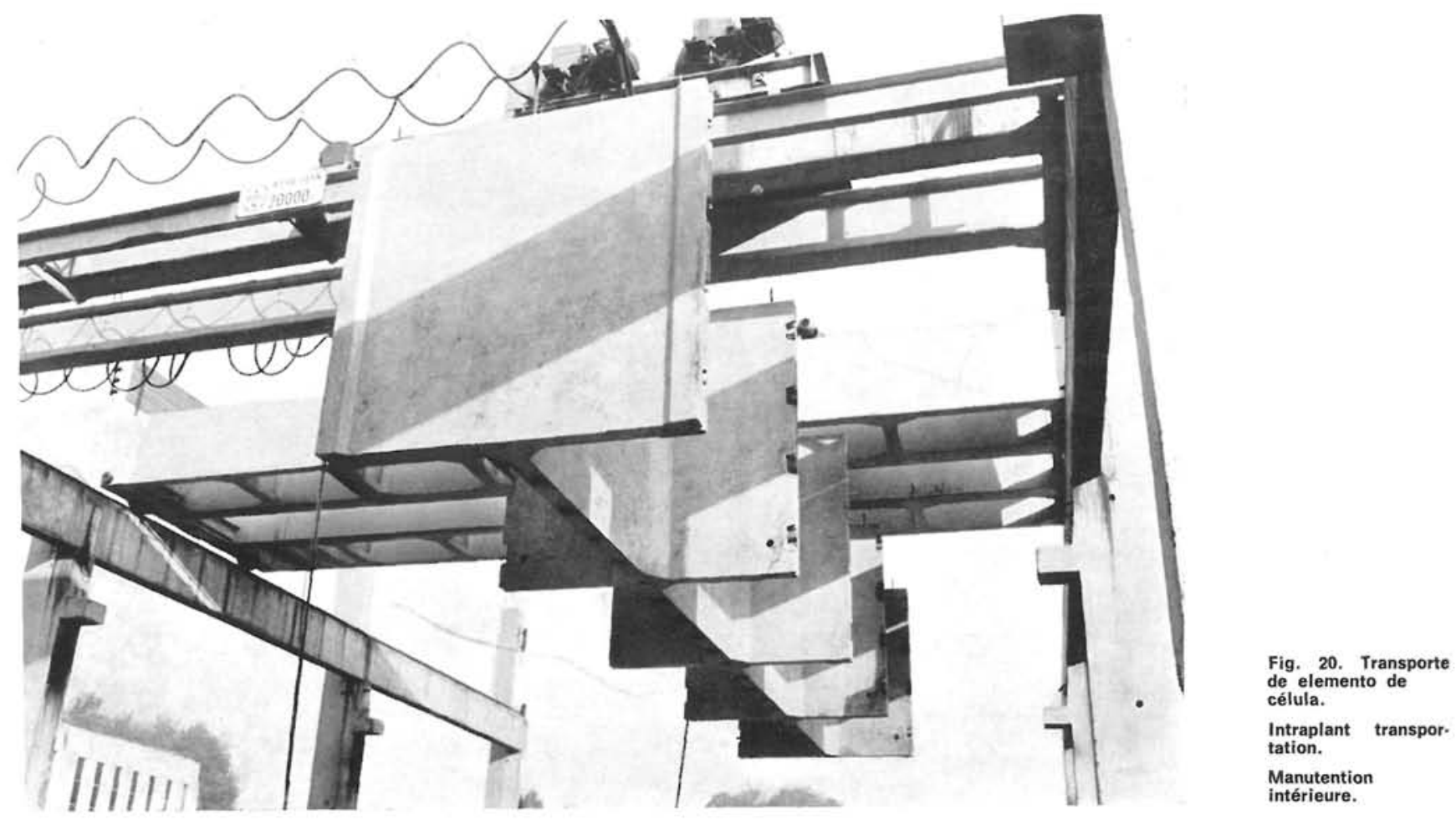

Las unidades del molde se unen entre sí de forma rígida mediante pernos o con barras de pata de cabra. La unión y la colocación del encofrado se realiza según un proceso bien definido, quedando garantizada la accesibilidad para el montaje y fijación de la armadura y de las piezas complementarias.

\section{Fabricación de las unidades de la célula del silo}

El hormigón se introduce dentro del molde mediante tolvas móviles en capas de $50 \mathrm{~cm}$ de altura, compactándose posteriormente con vibradores de aguja. No se han podido conseguir resultados suficientemente satisfactorios con vibración exterior. La duración del trabajo hubiera sido menor en el caso de vibración exterior, pero debería haberse tenido en cuenta el hecho de que con este sistema se hubieran producido muchos más poros en la super. ficie del elemento.

Se ha construido un elemento de célula por cada día de trabajo. La resistencia del hormigón al desencofrar era de una media de $220 \mathrm{kp} / \mathrm{cm}^{2}$.

El transporte interno de estos elementos se desarrollaba de la forma siguiente: a causa de su importante longitud, $11 \mathrm{~m}$, y un espesor medio del alma de $12,5 \mathrm{~cm}$, se ha tenido que recurrir a dos puentes-grúa para sacarlos de la nave de fabricación (véase fig. 20).

Desde la nave al depósito se ha utilizado un aparato de elevación porticado de una capacidad de $22 \mathrm{Mp}$. En todas estas manipulaciones no ha sido necesario prever una rigidización en el interior de los elementos.

\section{El almacenamiento}

En el almacenamiento de elementos tan largos, siempre son posibles las deformaciones. Las principales causas de estas deformaciones son las condiciones de almacenamiento y la insolación de una sola cara. Se pueden paliar en gran parte estas deformaciones depositando los elementos apoyados en tres puntos y no exponiendo más que la parte frontal al sol.

Los elementos se colocaron embutidos unos en otros en planta. Tres unidades de células han podido ser depositadas sobre las otras; de esta forma la superficie necesaria para el almacenamiento era, incluidos los accesos, de $10 \mathrm{~m}^{2}$ por elemento. 
Fig. 21. Elemento de célula du. rante su montaje.

Cell unit in assembly stage.

Unité de cellule en état de montage.

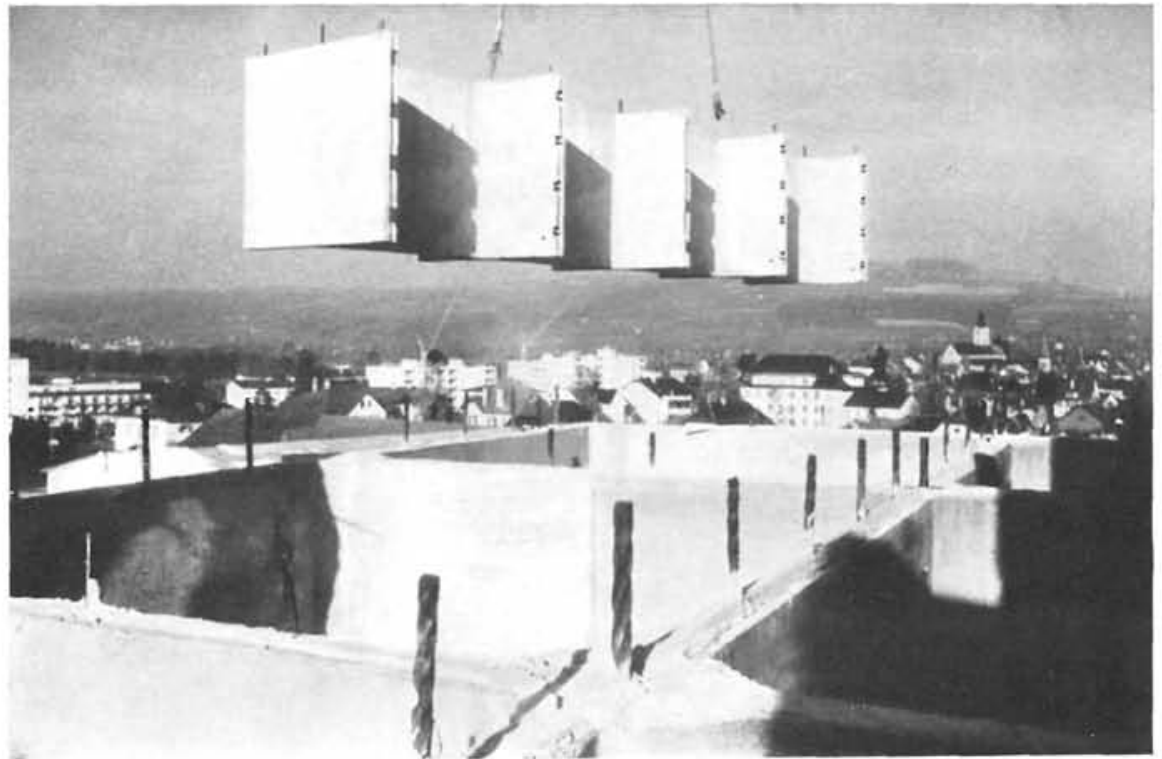

\section{Transporte a obra}

La carga de los elementos sobre un tractor de eje posterior móvil se hacía de nuevo con el aparato de elevación de pórticos. El puente rígido del tractor, de una longitud de $10 \mathrm{~m}$, impedia las deformaciones durante el transporte.

\section{Montaje y unión de las partes de las células}

El montaje y la unión de todos los elementos resistentes y de fachada de las construcciones UFAG y VLGZ se ha efectuado con una grúa, de $90 \mathrm{t}$, sobre neumáticos "Gottwald" (grúa-torre) equipada con una pluma levadiza. Momento de vuelco: $210 \mathrm{Mp} \cdot \mathrm{m}$; altura de arrollamiento: $70 \mathrm{~m}$.

Un grupo de 11 obreros especializados terminaron el montaje completo, incluidos los trabajos accesorios, en un tiempo neto de 13 semanas (ver fig. 21).

El peso de una célula de silo es de $18 \mathrm{t}$ como media.

Los elementos de la construcción VLGZ para piensos compuestos alcanzan un total de $5.050 \mathrm{t}$, que se repartió entre 923 elementos diferentes.

Como andamio interior se ha utilizado la plataforma de trabajo. Para el acabado de las juntas de fachada se colocó un andamio suspendido. La protección en el trabajo se aseguró mediante un emparrillado en voladizo recubierto de una red metálica.

\section{Recapitulación}

\section{Obra para piensos compuestos VLGZ (Sursee)}

Número de elementos prefabricados: 923 piezas (recepción, molino, silo y expedición).

Los elementos arrojaron un total de: aproximadamente $5.050 \mathrm{t}$; cada unidad de silo EH: $18 \mathrm{t}$; altura del silo: $44 \mathrm{~m}$; altura del molino: $23 \mathrm{~m}$ (10 plantas y techumbre).

Todos los ensambles verticales de los elementos resistentes, compuestos por un acero de espera que se introduce en una vaina de chapa de acero ondulada, se rellenan con un mortero blando Sika.

Las uniones verticales entre elementos de silo, así como las grandes paredes, se realizan con el anclaje de tracción (sistema: Ing. Huonder). Las losas del suelo y del techo se unen por soldadura.

Las juntas horizontales se ejecutan, después de un examen de las exigencias estáticas, bien con un mortero de cemento, bien con un mortero blando o con mortero adhesivo de epoxi (mortero adhesivo Sikadur). 


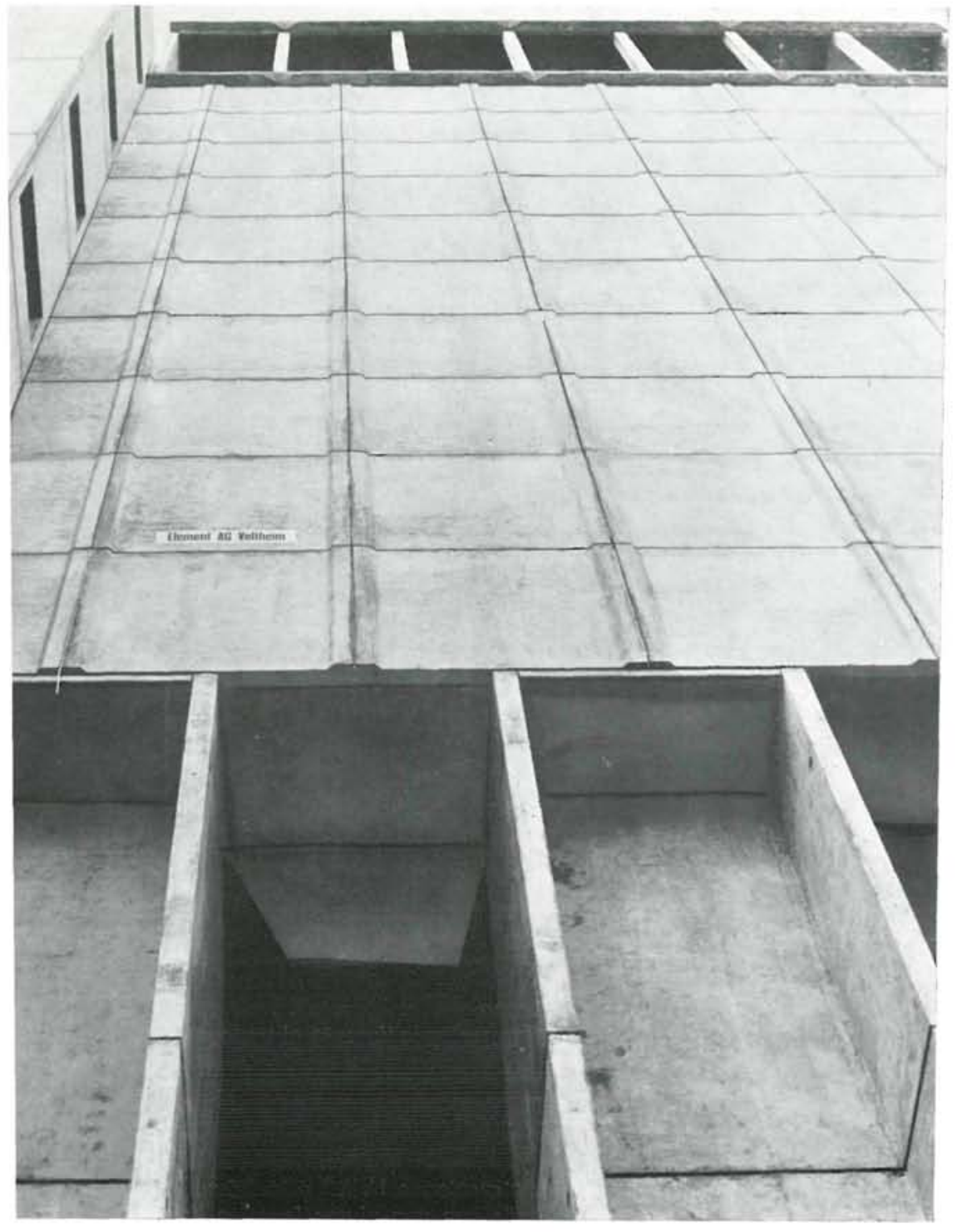

Fig. 22. Fachada del silo. Silo façade.

Façade de silo.
Las juntas verticales se llenan de forma uniforme con un mortero de cemento.

Duración del montaje exclusivamente: 13 semanas.

Grupo de trabajo: 11 hombres.

Grúa de montaje: Grúa sobre neumáti$\cos$ "Gottwald" de $90 \mathrm{t}$.

Momento máximo de vuelco: 210 $\mathrm{m} \cdot \mathrm{Mp}$.

Altura de arrollamiento: $70 \mathrm{~m}$.

Ordenes de montaje: por radiofonía.

Coste total de la construcción prefabricada:

Precio, a principios de 1969, aproximadamente: 1.150 .000 francos suizos, incluidos los honorarios del ingeniero.

Precio por $\mathrm{m}^{3}$ de las células del silo únicamente, montadas, sin tolvas de evacuación: aproximadamente 95 francos suizos.

Construcción UFAG para piensos minerales (Sursee)

Número de elementos prefabricados: 1.726 piezas (depósito, torre y silo).

Total de los elementos: $8.696 \mathrm{t}$ aproximadamente.

Máximo de un elemento de silo $\mathrm{EH}$ : $18 \mathrm{t}$ aproximadamente.

Altura del depósito: $14 \mathrm{~m}$.

Altura de la torre: $36 \mathrm{~m}$.

Altura del silo: $43 \mathrm{~m}$.

Las uniones horizontales y verticales se han solucionado de la misma forma que en la obra VLGZ.

La recepción se ha habilitado entre dos pilares en forma de $\mathrm{H}$, con elementos verticales y exteriores de cerramiento.

Duración probable del montaje: 19 semanas $\bullet$ Grupo de trabajo: 10 hombres $\bullet$ Grúa de montaje: igual que en VLGZ. Precio total de la construcción prefabricada (otoño 1969): aproximadamente 2.050 .000 francos suizos, incluidos los honorarios del ingeniero.

Precio por $\mathrm{m}^{3}$ de las células del silo, únicamente, acabadas y montadas, sin tolvas de evacuación: 100 francos suizos.

\section{résumé}

Innovations dans la construction de silos - Suisse

A. Huonder, Dipl. Ing.

P. Vajda, Dipl. Ing. collaborateu

Dans cet article les auteurs décrivent les caractéristiques, les dimensiones, les systè. mes de construction, le scellement des joints, les coffrages, le montage, etc. de ces sillos tout à fait préfabriqués, qui cons. tiuent une nouveauté remarquable quant à finition et la grande économie.

\section{summary}

Innovations in the construction of silos - Switzerland

A. Huonder, Dipl. Eng.

P. Vajda, Collaborating Dipl. Eng.

This article gives details on sizes, construc. tion, features, method of sealing joints, formwork, erection, etc. about these silos, which are totally prefabricated. They are a significant advance in construction time, quality of finish and total cost.

\section{zusammenfassung}

Nuerungen im Silobau - Schweiz

Dipl. Ing. A. Huonder

Dipl. Ing. P. Vajda, Mitarbeiter

Dieser Artikel gibt eine Beschreibung der technischen Eigenschaften, Dimensionen, Verschalungen, Montelu us wichtungen, im Fertigbau hergestellten Silos, die eine grossartige Neuheit darstellen im Hinblick grossartige Neuheit darstellen im Hinblick Fertigbearbeitung und grosse Wirtschaftlich keit. 